\title{
A DISCRICIONARIEDADE JUDICIAL E A DEFINITIVIDADE DA DECISÃO JUDICIAL: A TEORIA DE HART E AS CRÍTICAS APONTADAS POR DWORKIN
}

THE JUDICIAL DISCRETION AND A DEFINITIVE CHARATER TO JUDICIAL DECISION: THE HART'S THEORY AND CRITICALS POINTED BY DWORKIN

Maria Valentina de Moraes

Mônia Clarissa Hennig Leal

\section{RESUMO}

Questiona-se, diante da zona de penumbra defendida por Hart, a afirmação se de fato o direito é aquilo que os tribunais dizem que é e o papel que assume a discricionariedade nesse contexto. Utiliza-se do método dedutivo, sendo abordada a teoria de Hart e a questão da definitividade das decisões dos Tribunais supremos, analisadas as críticas de Dworkin e discutida a afirmação acerca do direito ser o que os tribunais dizem que é. Conclui-se que Hart preocupou-se em limitar a discricionariedade judicial, contudo, aceita que as decisões dos tribunais se incorporem ao direito e acabem sendo reproduzidas, demonstrando sua incompletude.

Palavras-chave: Discricionariedade. Dworkin. Hart.

\section{ABSTRACT}

Is questioned, before the penumbra zone defender to Hart, an affirmation if the law it's what the Courts say it is and the role of discretion in this context. It's 
use the deductive method, and is addressed the Hart's theory and the question about definitive character to decisions of Supreme Courts; too the Dworkin's criticism and is discuss the affirmation about to law it's what the Courts say it is. It can be said that Hart worried whit a judicial discretion limit, however, even defending the need of that is observed decisions standards, accepted that the tribunal decisions get incorporated to the law and begin to be reproduced, which demonstrates that law is incomplete.

Keywords: Discretion. Dworkin. Hart.

\section{INTRODUÇÃo}

A classificação das teorias do direito, especialmente no que se refere à classificação dos positivistas jurídicos, permeia discussões que tentam enquadrar determinado autor em alguma corrente. Ocorre que, embora possuam semelhanças que permitam uma distinção aproximada da corrente onde se encontram, os positivistas ${ }^{1}$, e aqui analisados Herbert Hart e Ronald Dworkin, trazem em suas teorias significativas oposições. Frente a isso, busca-se discutir o papel dos Tribunais no sistema jurídico e a força da discricionariedade em sua atuação diante da textura aberta ou zona de penumbra reconhecida por Hart e objeto de crítica por parte de Dworkin e frente à noção de resposta correta que é debatida por este último.

Utiliza-se a teoria do autor como elemento central da discussão, bem como as críticas apontadas por Dworkin à teoria hartiana e as interpretações realizadas pelo próprio Hart em seu pós-escrito quanto a essas críticas, onde apresenta considerações quanto à plausibilidade das mesmas e contra argumentos que justificam sua teoria. A escolha pelo recorte quanto aos dois autores guarda relação com o tema da discricionariedade judicial, que é um dos principais ${ }^{2}$ pontos de divergência nas teorias. Para Hart existiriam casos não regulados juridicamente, tornando o direito incompleto e lacunoso, enquanto que, para Dworkin e a noção de direito como integridade e composto por princípios condutores das decisões, a busca pela melhor interpretação conduziria a uma resposta mais correta, pautada em elementos inseridos no próprio direito ou até mesmo presentes na moral. 
Assim, a problemática envolvendo a discricionariedade judicial dos tribunais - mais ainda dos Tribunais Supremos -, que é reconhecida e aceita por Hart ao tratar da definitividade dessas decisões, continua a ser objeto de crítica dos teóricos do direito. A teoria de Dworkin, que enfrenta a mesma preocupação quanto aos limites dessa discricionariedade judicial, avança ao reconhecer a existência de princípios que norteiam o direito e que, ainda que mais abstratos, definem um conteúdo a ser seguido, todavia, como apontam seus críticos, não resolve a questão em virtude do mesmo motivo: a possibilidade de uma discricionariedade que conduza a um solipsismo judicial diante das lacunas (sejam elas linguísticas ou do próprio direito) existentes e do conteúdo aberto característico dos princípios jurídicos.

Parte-se, então, empregando o método dedutivo, da análise da definitividade das decisões judiciais sob a perspectiva de Herbert Hart - passando por elementos como a autoridade e a lei posta, que é característica quase que determinante do positivismo jurídico -, discutindo-se, posteriormente, as críticas apresentadas por Dworkin no que se refere a essa questão e à discricionariedade judicial, bem como o posicionamento de Hart no tocante a tais críticas, questionando-se, por fim, se a assertiva de que o direito é aquilo que os tribunais dizem que é - defendida pelos céticos e discutida por Hart -constitui-se, de fato, como uma verdade ou encontra limitação em determinados elementos presentes no próprio direito.

\section{A DEFINITIVIDADE DAS DECISÕES PROFERIDAS PELOS TRIBUNAIS NA TEORIA HARTIANA: O POSITIVISMO JURÍDICO E A NORMA POSTA E IMPOSTA}

O positivismo jurídico, como uma das teorias que analisam o direito, compreende um universo de diferentes teóricos que estudam a norma posta, voltando-se à normatividade como uma característica principal do direito. Em resumo, "o positivismo jurídico indica a preocupação com o estudo do direito posto (e também imposto). Interessa o estudo dos atos que impõem normas, como indica o termo alemão Gesetz (lei), 
oriundo do verbo setzen (pôr, assentar, sentar)" (DIMOULIS, 2006, p. 68, grifado no original). Para Herbert Hart, considerado um positivista analítico - diferentemente de Kelsen que é considerado um positivista metodológico -, a noção de autoridade figura como um ponto crucial de sua teoria, sendo ela definida quando o mesmo defende a existência de regras primárias e secundárias, onde as segundas se referem às outras normas do ordenamento e outorgam competências, sendo possível, através destas, identificar as normas primárias, que outorgariam obrigações (HART, 1994). Hart é conhecido ainda, frente a essa ligação entre normas primárias e secundárias, por justificar o sistema jurídico em sua regra de reconhecimento, que estaria presente no próprio sistema e seria uma prática e, portanto, de caráter fático - distinguindo-se da norma fundamental de Kelsen que seria pressuposta.

Assim, como coloca Ferraz Junior (2011, p. 49), “o direito é um conjunto de normas que valem por força de serem postadas pela autoridade constituída e só por força de outra posição podem ser revogadas", o que denota a importância destinada pelo positivismo jurídico à questão da autoridade legitimada (seja ela o legislador ou mesmo os tribunais) por uma regra - de caráter secundário - que, por sua vez aplica e produz decisões legítimas. Ao sustentar que o direito é um sistema de integração de regras primárias e secundárias e trazer a linguagem para o debate jurídico, Herbert Hart passou a ocupar um espaço entre o paraíso dos formalistas e o pessimismo dos céticos ${ }^{3}$ e, no que se refere à evolução da teoria hartiana em relação à teoria kelseniana, Bitencourt (2013, p. 33) observa que Hart "organizou sua teoria baseando-se na conceituação de normas primárias e secundárias e de como estas interagem entre si".

Em sua obra "O Conceito de direito", o autor contrapôs as críticas apresentadas pelos céticos, apresentando as incoerências que sustentavam. Pode-se dizer que, para os céticos, falar sobre regras se caracterizaria como um mito, vez que o direito seria composto pelas decisões dos tribunais - reforçando a máxima de que o direito é o produto do que os tribunais decidem e, logo, torna-se o que os tribunais dizem que ele é. Todavia, a própria existência desses tribunais dotados de autoridade para emitirem decisões, sob a ótica da existência de 
regras primárias e secundárias, configuraria a existência de tais regras secundárias, já que são essas que outorgam a competência dos tribunais (HART, 1994). Já o ceticismo moderado, assume, contudo, a existência de regras que outorgam competência e que instituem os tribunais, mas sustentam que as regras apenas se tornam direito depois de serem aplicadas pelos tribunais, servindo, até então, como fonte do direito, afirmando igualmente que os tribunais não estariam sequer vinculados pelas regras ao decidirem (HART, 1994).

Hart (1994, p. 147), ainda que não adepto do ceticismo, reconhece o papel significativo que os tribunais terão na aplicação do direito e, sob a ótica do sistema da commom law no qual estava inserido, analisa, sustentando que "não há nenhuma formulação dotada de autoridade ou unicamente correcta (sic) de qualquer regra que deva extrair-se dos casos", que:

[...] seja qual for o estatuto dotado de autoridade que uma regra extraída de um precedente possa ter, é compatível com o exercício pelos tribunais por ela vinculados dos dois tipos seguintes de actividade (sic) criadora ou legislativa: por um lado, os tribunais que decidem um caso posterior podem chegar a uma decisão oposta à contida em num precedente, através da interpretação restritiva da regra extraída do precedente e da admissão de alguma excepção (sic) a ela que não foi antes considerada ou, se foi considerada, foi deixada em aberto. [...] Por outro lado, ao seguir um precedente anterior, os tribunais podem afastar uma restrição descoberta na regra, tal como foi formulada a partir do caso anterior, com o fundamento de que tal restrição não é exigida por qualquer regra estabelecida por lei ou por precedente anterior. Fazer isto significa ampliar a regra (HART, 1994, p. 148).

A função de dizer o direito que desempenham os tribunais é aceita por Hart - a partir da interação de regras primárias e secundárias -, o qual defende a existência de uma zona de textura aberta, ou zona de penumbra, onde existem "áreas de conduta em que muitas coisas devem ser deixadas para serem desenvolvidas pelos tribunais", considerando a existência desse espaço como necessária e não apenas uma consequência do próprio sistema (HART, 1994, p. 148). Assim, os tribunais vão "variando suas decisões em decorrência das ponderações decorrentes da aplicação do 
direito a esses casos. É o espaço para a discricionariedade da decisão judicial" (BITENCOURT, 2013, p. 35). Nos casos onde se encontra essa textura aberta, apenas pode se esperar algo relativamente previsível das decisões do tribunal, de forma que essas estejam de acordo com um padrão de conformidade estabelecido (HART, 1994). A linguagem, nesse aspecto, apresenta-se como uma das causas dessa textura aberta, pois, ao se buscar, por meio de uma lei, antever e regular condutas, a mesma torna-se abstrata e geral, sendo "a incerteza na linha de fronteira [...] o preço que deve ser pago pelo uso de termos classificatórios gerais em qualquer forma de comunicação que respeite a questões de fato" (HART, 1994, p. 141).

Streck (2010, p. 227, grifado no original), referindo a ideia dos positivistas de muitas respostas para uma questão, aponta como principal característica do positivismo essa "discricionariedade, que ocorre a partir da 'delegação' em favor dos juízes para a resolução dos casos difíceis (não 'abarcados' pela regra)”. Em mesma linha, Hart reconhece uma das dificuldades apresentada pela aceitação de uma discricionariedade judicial, criticando a postura que é adotada por juízes na Inglaterra - e que, pode-se dizer, é uma crítica atual e que cabe também ao Brasil -, onde "os tribunais frequentemente negam qualquer função criadora desse tipo e insistem em que a tarefa apropriada da interpretação da lei e do uso dos precedentes é, respectivamente, procurar a 'intenção do legislador' e o direito que já existe" (HART, 1994, p. 149, grifado no original).Nesse sentido, interessante pontuar a crítica moderna de Streck (2010, p. 223) ao decisionismo que pode se instalar diante desses fatores antes apresentados e que, embora discutidos em outra década e país, são diretamente aplicados à realidade brasileira:

[...] por vezes, a "vontade da lei" e a "essência da lei" devem ser buscadas com todo o vigor; em outras, há uma ferrenha procura pela solipsista "vontade do legislador"; finalmente, quando nenhuma das duas orientações é "suficiente", põe-se no topo a "vontade do intérprete", colocando-se em segundo plano os limites semânticos do texto, fazendo soçobrar até mesmo a Constituição. 
Mesmo diante dessas questões controversas envolvendo a discricionariedade judicial, as quais foram reconhecidas já por Hart em sua teoria e que ainda figuram como crítica de diversos autores contemporâneos, Herbert Hart (1994, p. 155) sustenta a definitividade das decisões judiciais, vez que "um supremo tribunal tem a última palavra a dizer sobre o que é o direito", distinguindo, todavia, entre a definitividade dessas decisões e sua infalibilidade ao considerar que uma decisão errada não possuirão efeito jurídico, podendo ser revista por meio de alguma forma de revisão (HART, 1994). Deve ser prevista, portanto, uma forma de correção dessas decisões proferidas por um tribunal, como, por exemplo, um recurso, mas novamente esse recurso será analisado por um tribunal que terá a última palavra sobre a questão ${ }^{4}$ e que é composto por pessoas que são, por sua essência, falíveis, existindo sempre um risco de que sejam cometidos abusos e erros (HART, 1994).Reforçando essa linha de pensamento, Hart (1994, p. 155 , grifado no original) saliente que "a afirmação de que o tribunal estava <<errado>> não tem consequência dentro do sistema”, o que denota que "o positivismo não 'mistura ou confunde validade e justiça das normas"”5 (DIMOULIS, 2006, p. 114).

Essa textura aberta ou mesmo zona de penumbra como chama o autor, deixa um grande espaço para a criação do direito pelos tribunais e, após proferida uma decisão, essa só pode ser modificada por uma nova lei criada por uma autoridade competente (HART, 1994). E em um sistema de controle de constitucionalidade, lembra Hart (1994, p. 158), "sobre a interpretação de tal [lei], os tribunais terão de novo a mesma última palavra dotada de autoridade", como um ciclo que não se encerra. Novamente se reafirma "a competência conferida a uma autoridade ou pessoa para a criação de certa espécie de norma” como uma das condições mais importantes do positivismo, onde tanto o legislador precisa ter autoridade para a edição da norma, como o tribunal para sua revisão (DIMOULIS, 2006, p. 114).Frente a todos esses aspectos, o questionamento se o direito é aquilo que os tribunais dizem que ele é volta a ser objeto de crítica, a qual será abordada no terceiro tópico.

Pode se dizer, utilizando-se das palavras de Bitencourt (2013, p.46, grifado no original) que "Hart evolui ao admitir um caráter mais factual, contudo, também não explicita com que base os juízes decidiram no 
espaço da discricionariedade - zona de penumbra - valendo-se de um aspecto de cunho quase 'intuitivo'". E sobre esse aspecto, especialmente, se volta a crítica de Dworkin à Hart, que passa a ser discutida.

\section{A DISCRICIONARIEDADE E AS CRÍTICAS DE DWORKIN À HART: OS CASOS JURIDICAMENTE NÃO REGULADOS}

Como um crítico do positivismo analítico de Herbert Hart, Ronald Dworkin apresenta algumas críticas à teoria hartiana no que se refere à discricionariedade judicial sustentada pelo autor, o que faz com que, como destaca Streck (2010, p. 227) "a holding da discussão encontra-se nas críticas dirigidas a Herbert Hart por Ronald Dworkin, para quem o juiz não possui discricionariedade para resolver os hard cases". Hart, no pós-escrito de sua obra "O Conceito de Direito", deixa clara a divergência existente:

o conflito directo (sic) mais agudo entre a teoria jurídica deste livro e a teoria de Dworkin é suscitado pela minha afirmação de que, em qualquer sistema jurídico, haverá sempre certos casos juridicamente não regulados em que, relativamente a determinado ponto, nenhuma decisão em qualquer dos sentidos é ditada pelo direito e, nessa conformidade, o direito apresenta-se como parcialmente indeterminado ou incompleto. [...] Esta imagem do direito, como sendo parcialmente indeterminado ou incompleto, e a do juiz, enquanto preenche as lacunas através do exercício de um poder discricionário limitadamente criador de direito, são rejeitadas por Dworkin (HART, 1994, p. 335).

Para Hart, dentro da estrutura de regras, não só existe, como deve existir, um espaço de discricionariedade judicial, onde fatores não jurídicos devem ser levados em conta na decisão, não configurando-se o direito como um sistema completo e inteiro, sendo uma ilusão acreditar que existe apenas uma forma de se suprirem as lacunas que existem no sistema de regras (MACCORMICK, 2010). A crítica de Dworkin, o qual possui um conceito de direito diferente do apresentado por Hart, reside justamente no fato de o mesmo compreender o direito como integridade e defender a existência de princípios norteadores das 
decisões judiciais, devendo o juiz corrigir o direito por meio da moral, não sendo um defensor da discricionariedade judicial, como por vezes se afirma. Dimoulis é um dos autores que critica a leitura realizada da teoria de Dworkin, afirmando que o mesmo defendia uma limitação na discricionariedade do Judiciário - e não o contrário, como é afirmado no Brasil -, devendo os juízes decidirem em consonância com os juízos morais da sociedade (DIMOULIS, 2006). A teoria de Dworkin"não só aceita a discricionariedade judicial, como busca limitá-la a uma série de preceitos como 'princípio da integridade' que devem guiar os juízes em sua práxis judicial” (BITENCOURT, 2013, p.40, grifado no original).

Dworkin apresenta o conceito de direito como integridade pelo qual existem proposições verdadeiras sempre que as mesmas são decorrentes de princípios como, por exemplo, o da justiça e da equidade. Afirma que para o direito como integridade, o juiz deve continuar reinterpretando até mesmo aquilo que já interpretou (DWORKIN, 2007a), sendo o direito, portanto, "tanto o produto da interpretação abrangente da prática jurídica quanto sua fonte de inspiração" (DWORKIN, 2007a, p. 273). Para o direito como integridade, como já referido, deve-se aceitar a ideia de que o direito é pautado sobre princípios como o da justiça, do devido processo e da equidade, pretendendo essa corrente que o direito se torne uma comunidade de princípios. Deve se buscar, dessa forma, a melhor interpretação possível segundo critérios que são ditados pelos princípios (DWORKIN, 2007a). Como observa Guest (2010, p. 63, grifado no original), "devemos, na visão de Dworkin, extrair o melhor sentido moral dos argumentos".

Utilizando o exemplo do juiz Hércules ${ }^{6}$, Dworkin sustenta que as decisões tomadas devem ser pautadas na integridade, a qual possuiria ligação direta com a fraternidade e um ideal de justiça, diante de uma sociedade que não é a ideal (GUEST, 2010). Para ele a interpretação não pode resumir-se apenas a buscar da intenção do emissor de uma mensagem e sim ser realizada de forma a se buscar o melhor exemplo da prática envolvida, sendo assim, deve se recorrer a teoria que permitir a maior realização dos princípios que dão sentido à prática (ATIENZA, 2010). A Teoria de Dworkin apresenta, assim, pontos que são opostos ao que defende Hart, sendo sensível a questão da discricionariedade frente 
a essas diferentes concepções que permeiam as duas teorias e ao que compõe o conceito de direito para cada uma delas.

No que se refere às divergências apresentadas nas duas teorias, coloca Atienza (2010, p. 268), que, para alguns críticos do positivismo analítico, como é Dworkin, o direito "no pude ser visto exclusivamente como una realidad ya dada, como el producto de una autoridad [...], sino (además y fundamentalmente) como una práctica social que incorpora una pretensión de justificación o do corrección”, o que reflete a busca pela melhor prática jurídica e melhor resposta e, ainda, demonstra uma evolução no sentido de uma maior preocupação com o sentido da decisão e não apenas com a legitimidade da autoridade que a profere - embora não se possa afirmar que Hart não se preocupe com a questão, o fazendo, mas de forma mais superficial do que Dworkin.

Entendendo que o argumento que sustenta na imprecisão da linguagem o fato de não existirem respostas corretas é falho, Dworkin (2007b, p. 188) afirma que "a popularidade dessa ideia baseia-se na incapacidade de distinguir entre o fato e as conseqüências da imprecisão na linguagem jurídica consagrada", sendo que "os juristas realmente discordam quanto às técnicas de interpretação e explicação usadas para responder a tais questões" (DWORKIN, 2007b, p. 194). Sobre a inexistência de uma resposta certa, analisa o autor que:

[...] a questão, portanto, de se existem casos sem nenhuma resposta certa em um determinado sistema jurídico - e se tais casos são raros ou numerosos - não é uma questão empírica comum. Acredito que tais casos, se é que existem, devem ser extremamente raros nos Estados Unidos e na Grã-Bretanha. [...] E nem provavelmente terá êxito [alguém] se tentar encontrar exemplos efetivos de casos sem nenhuma reposta certa numa investigação, caso a caso, dos relatos jurídicos (DWORKIN, 2007b, p. 215).

Já Hart (1994, p. 336) considera a possibilidade de que essa resposta correta não exista para todos os casos, abrindo espaço à discricionariedade -no que é criticado por Dworkin -, colocando que "haverá pontos em que o direito existente não consegue ditar qualquer decisão que seja correcta (sic) e, para decidir o caos em que tal ocorra, o juiz deve exercer os seus poderes de criação do direito". Complementa ainda que é "porque 
estamos na zona de textura aberta da regra fundamental do sistema. Aqui pode surgir a todo o momento uma questão para a qual não haja uma resposta - só respostas", divergindo de um dos principais pilares da teoria de Dworkin, qual seja, a existência de uma resposta mais correta (HART, 1994, p. 165).

Nesse ponto percebe-se claramente as duas abordagens distintas trazidas pelos autores, onde, no primeiro caso, configura-se um constante reforço à noção principiológica de Dworkin, pela qual existem princípios que embasam seu conceito de direito como integridade e que esses diminuem significativamente a possibilidade de que não existam respostas para uma questão, o que vem aliado à ideia de resposta correta. Noutro caso, Herbert Hart, que não teve em sua teoria grande preocupação com os princípios, centrando-se em um sistema de normas que daria ao direito a característica de ser incompleto e com lacunas, as quais seriam supridas por meio da discricionariedade judicial. Essa questão foi, inclusive, objeto de crítica por parte de MacCormick (2010, p. 44) ao escrever sobre a teoria do autor, onde este salienta que "a teoria de Hart falha de modo significativo ao não lançar nenhuma discussão essencial acerca dos princípios paralela à sua discussão das regras".

Tratando sobre dimensões que forneceriam um critério de justificação, Dworkin (2007b, p. 214) volta a afirmar que é "ainda mais improvável que algum caso específico não tenha nenhuma resposta certa”, sendo importante observar que embora seja a principal crítica do autor à Hart, esse, em seu pós-escrito, ainda que reconhecendo a importância que detenham os princípios no direito, negou que os mesmos pudessem conduzir "sempre, ou mesmo frequentemente" a uma resposta correta, enfraquecendo a discricionariedade judicial (GUEST, 2010). Outra crítica que foi assimilada por Hart se refere à falta de legitimidade democrática que teriam os juízes e os tribunais para criarem o direito - atuando como legisladores e não meros aplicadores -, crítica essa que se mostra sempre atual, caracterizando-se como uma das principais objeções ao controle de constitucionalidade e, embora a mesma seja recorrente, Müller (2013, p. 56, grifado no original) traça uma interessante lógica quanto a tal crítica: 
[...] os poderes "executantes", isto é Executivo e Judiciário, não estão apenas instituídos e não são apenas controlados conforme o Estado de Direito; estão também comprometidos com a democracia. 0 povo ativo elege os seus representantes; do trabalho dos mesmos resultam (entre outras coisas) os textos das normas; estes são, por sua vez, implementados nas diferentes funções do aparelho de Estado; [...] Tudo isso forma uma espécie de circulação de atos de legitimação, que em nenhum lugar pode ser interrompido (de modo não democrático). Esse é o lado democrático que foi denominado estrutura de legitimação".

Muitas são as respostas dadas a essa crítica ao longo do tempo: a legitimação indireta dos juízes e tribunais que ocorreria, como sustenta Müller acima; a impossibilidade de se ter um Estado Democrático sem uma jurisdição constitucional, como observa Streck (2002); e, ainda, que "isso é o preço que tem de pagar-se pela consagração de limites jurídicos ao poder político", como rebate Hart a Dworkin (1994, p. 339) em seu pós-escrito. Todavia, esse preço a ser pago pode ser atenuado se existirem limitações à atuação desses poderes e também uma barreira para que promovam grandes reformas em códigos, restringindo sua atuação à situações específicas que se mostrem nos casos concretos, não representando a atuação judicial, assim, uma grande ameaça à democracia (HART, 1994). Sendo assim, ainda que Hart defenda a necessária existência de um espaço de discricionariedade judicial, não defende que a mesma deve ser ilimitada, de forma que os tribunais passem a ditar o que é o direito sem maiores parâmetros, como se verá.

\section{OS TRIBUNAIS E A CRIAÇÃO DO DIREITO DIANTE DOS CASOS NÃO REGULADOS DE HART E DA RESPOSTA CORRETA DE DWORKIN: O DIREITO É AQUILO QUE OS TRIBUNAIS DIZEM QUE É?}

Toda a discussão referente à discricionariedade judicial e à definitividade das decisões dos Supremos Tribunais faz com que, muitas vezes, se aponte que o direito se torna "aquilo que os tribunais dizem que ele é" e Hart demonstra preocupação em esclarecer essa questão em sua 
obra. Utilizando o exemplo da regra de pontuação de um jogo, o autor traça uma comparação com o que seria a discricionariedade do marcador:

[...] podemos distinguir um jogo normal de um jogo de $<<$ discricionariedade no marcador $>>$ simplesmente porque a regra de pontuação, embora tenha, como outras regras, a sua textura aberta em que o marcador deve exercer uma escolha, possui, contudo um núcleo de significado estabelecido. É desse núcleo que o marcador não é livre de afastar-se e que, enquanto se mantém, constitui o padrão de pontuação correcta (sic) e incorrecta (sic) [...]. É isto que torna verdadeiro dizer que as determinações do marcador não são infalíveis, embora sejam definitivas. 0 mesmo é verdade quanto ao direito (HART, 1994, p. 157, grifado no original).

Os "padrões de decisão judicial correta", nesse sentido, decorrem da existência de uma parte central das regras de um sistema que é bem definida e que configura-se como algo a ser respeitado nas decisões dos tribunais, não sendo eles contestáveis, devendo ser seguidos pelos magistrados (HART, 1994). Esses padrões, no entender de Hart (1994, p. 161) tem a função de, na zona de textura aberta, "limitar o seu caráter discricionário, embora sem o excluir",oferecendo uma margem mais reduzida à atuação judicial e alguma segurança no que se refere a como irá decidir o tribunal, "funcionando como uma espécie de núcleo fixo, ou seja, na maioria dos casos previsíveis" (BITENCOURT, 2013). Nem todas as regras do sistema - e pode se dizer, a menor parte delas - possuirá essa textura aberta ou uma penumbra quanto ao seu conteúdo, sendo a discricionariedade judicial reservada aos hard cases, onde o direito demonstra a sua incompletude.

MacCormick (2010, p. 169, grifado no original), analisando a teoria de Hart,sintetiza a questão relativa à diferença existente quanto aos casos em que há uma "penumbra da dúvida" sobre determinados conceitos ou sentidos, salientando que "existe um 'núcleo de certeza', isto é, exemplos claros de coisas [...] se encaixam perfeitamente no sentido do termo em questão. Mas há também [...] casos-limite que não são abrangidos com clareza ou sem ambiguidade pelo termo usado". Em ambos os casos "recorre-se a uma espécie de 'acordo moral'; no primeiro, os juízes acessam esse acordo preestabelecido e, no segundo, possuem liberdade para “criar”, como esclarece Bitencourt (2013, p. 36).Onde há esse núcleo 
de certeza, a discricionariedade judicial não tem espaço, fazendo com que não existam maiores discussões nas decisões - ao menos no que se refere aos termos envolvidos no embate. Do contrário, diante da penumbra, a interpretação não é ilimitada, sendo pautada também pelos cânones da interpretação, os quais diminuem o campo de incerteza, mas não tem o condão de eliminá-la, uma vez que esses cânones podem ser compostos também por termos gerais e não tem como indicar a interpretação do seu próprio conteúdo (HART, 1994).

Para Dworkin, como já referido, além dos cânones interpretativos, os princípios e até mesmo a moral serviriam para ocupar os espaços onde os juízes precisassem decidir algum hard case. Contudo, Hart não se deteve em sua teoria à análise dos princípios, voltando-se somente ao sistema de regras jurídicas, mas "como regras jurídicas são uma espécie de regras sociais na teoria de Hart, não há motivo para negar a possibilidade de que haja princípios jurídicos, valores jurídicos como standarts e outros standarts jurídicos além das regras jurídicas" (MACCORMICK, 2010, p. 173 , grifado no original).

Dentro desse contexto, embora Dworkin se apresente como um crítico de Hart no tocante à discricionariedade judicial, se mostra oportuno salientar, como traz, Streck (2010, p. 227, grifado no original), que:

[...] por outro lado, parece despiciendo acentuar ou lembrar que a crítica à discricionariedade judicial não é uma "proibição de interpretar". Ora, interpretar é dar sentido (Sinngebung). É fundir horizontes. E direito é um sistema de regras e princípios, "comandado" por uma Constituição. Que as palavras da lei (lato sensu) contêm vaguezas e ambiguidades e que os princípios podem ser - e na maior parte das vezes são - mais "abertos" em termos de possibilidades de significado, não constitui nenhuma novidade. 0 que deve ser entendido é que a aplicação desses textos (isto é, a sua transformação em normas) não depende de uma subjetividade assujeitadora [...] como se os sentidos a serem atribuídos fossem fruto da vontade do intérprete.[...] 0 "drama" da discricionariedade aqui criticada é que esta transforma os juízes em legisladores. [...] Mas não é esse o tipo de criação judicial que está em causa no debate Dworkin-Hart e, tampouco, nas críticas que faço ao positivismo à luz da hermenêutica filosófica. 
A interpretação, desse modo, sempre fará parte da atividade judicial, seja quanto a termos ou mesmo aos fatos. A questão, todavia, é saber como essa atividade judicial, que encontrará casos não regulados, irá refletir no direito e se a mesma pode ter como consequência a criação do direito, sendo "apenas aparentemente paradoxal dizer que os juízes criam, em certo grau, o Direito em casos difíceis, ou que eles o fazem ao aplicar standarts jurídicos existentes" (MACCORMICK, 2010, p. 175). Há que se considerar, porém, que Hart (1994, p. 336), em seu pós-escrito, explica que «é importante que os poderes de criação que eu atribuo aos juízes, para resolverem os casos parcialmente deixados por regular pelo direito, sejam diferentes dos de um órgão legislativo», demonstrando que não foi ingênuo ao considerar o espaço de discricionariedade - e, talvez, criação - judicial que estaria a disposição dos juízes.

Questiona Hart (1994, p. 166), então, "como pode uma constituição atribuir autoridade para dizer o que é a constituição?” e se é assim, quem detém a autoridade para tal pode dizer o que é a constituição? E isso será ela? Todas essas questões, que trazem consigo debates sobre a discricionariedade judicial, sobre a existência de uma resposta correta - como um condição de atuação dos Tribunais ao decidirem - e, especialmente, sobre se o direito é aquilo que os tribunais dizem que ele é. Para Hart (1994, p. 166), essa atribuição da Constituição é uma "condição necessária":

[...] o paradoxo desaparece, se nos lembrarmos que embora cada regra possa ser de teor duvidoso em certos pontos, é, na verdade, uma condição necessária de um sistema jurídico existente que nem toda a regra esteja sujeita a dúvidas em todos os pontos. A possibilidade de os tribunais disporem de autoridade em certo tempo dado para decidirem essas questões de limite respeitantes aos critérios últimos de validade, depende apenas do facto (sic) de que, nesse tempo, a aplicação de tais critérios a uma vasta zona do direito, incluindo as regras que atribuem autoridade, não suscita dúvida, embora o respectivo alcance e âmbito precisos as suscitem.

O argumento utilizado por Hart denota a aceitação de que existem áreas não reguladas onde é imprescindível uma atuação por parte dos tribunais para que o sistema de regras e do próprio direito não seja imobilizado toda vez que algum desses casos difíceis se apresentar e 
assumindo certo cepticismo, reconhece que o "que torna possível estes desenvolvimentos notáveis pelos tribunais das regras mais fundamentais é, em grande medida, o prestígio obtido [...] a partir dos actos (sic) indiscutivelmente regidos pelas regras sobre as zonas vastas e centrais do direito" (HART, 1994, p. 167). Assim, quando os tribunais decidem e essa decisão passa a ser utilizada como um parâmetro, a mesma passa a fazer parte do direito, incorpora-se a ele (HART, 1994). Nesses casos, pode-se dizer, há uma criação do direito que é validada diante da impossibilidade de existência de uma legitimação prévia e constante dos tribunais e que se incorpora ao direito por ocupar uma parcela muito pequena de decisões (ao menos em tese) que não foram reguladas por uma lei e que foram emitidas por um tribunal com "prestígio" (HART, 1994).

0 fato dessas decisões serem corretas ou incorretas não foi objeto de desenvolvimento do autor, sendo essa uma preocupação de Dworkin, para quem, se pode dizer que o direito não é o que os tribunais dizem que é, existindo uma resposta certa que deve ser buscada. Relativamente a essa questão, entende-se que Streck (2010, p. 229) resume bem a controvérsia quanto à resposta correta e ao papel que os tribunais devem possuir, vez que "a resposta não é nem a única e nem a melhor: simplesmente se trata da 'resposta adequada à Constituição', isto é, uma resposta que deve ser confirmada na própria Constituição, na Constituição mesma”. O problema, contudo, é saber quem vai dizer quando ela está adequada à Constituição.

\section{CONCLUSÃO}

Por todo o exposto, pode se dizer que a existência de uma autoridade legitimada para a criação de regras - legislador - e para a aplicação delas - os tribunais - é um dos principais aspectos que cerca a teoria de Hart e que acompanha os positivistas em suas teorias. Hart, que não caracterizase nem como um cético nem como um formalista, defende que o direito não é apenas aquilo que os tribunais dizem que ele é, como pretendiam os céticos, entendendo que existem regras - de caráter secundário - que lhes outorgam competência. 
A discricionariedade judicial defendida pelo mesmo, e que é alvo de crítica por parte de Ronald Dworkin, é compreendida por Hart como algo necessário, um espaço que deve ser deixado para a atuação judicial onde os juízes decidirão os casos limites, que não encontrem uma regulação jurídica. Esse espaço o autor denomina zona de textura aberta ou zona de penumbra. Já Dworkin, que sustentava o direito como integridade e pautado também em princípios, defendia uma limitação dessa discricionariedade judicial, sustentando que os magistrados deveriam extrair o melhor argumento moral em suas decisões, devendo corrigir o direito por meio da moral.

Todavia, Hart não sustentou uma discricionariedade ilimitada aos tribunais, mas defendeu que esta irá existir em uma parcela muito menor de casos onde essa penumbra da dúvida se manifeste, sendo que, nos demais casos, haverá um núcleo de certeza do qual o julgador não poderá se afastar. Aceita o autor, ainda, que alguns casos não possuirão uma melhor resposta, contrariando à crítica de Dworkin ao defender que os princípios sempre, ou na maioria das vezes, irão funcionar como condutores à essa resposta certa.

Por fim, embora Hart compreenda que a discricionariedade é necessária, não defende que o direito seja aquilo que os tribunais dizem que ele é, mas observa que nesses casos em que o direito deixou uma margem (textura aberta) ou mesmo foram utilizados sentidos ambíguos, será dos tribunais supremos a última palavra sobre a questão, como definido pela própria Constituição. Entende que as decisões referentes a esses casos irão se inserir no direito e passarão a ser entendidas como tal - casos em que o direito será aquilo que os tribunais dizem que é - e reproduzidas também como tal, contudo, isso ocorrerá por dois fatores: serão decisões referentes à uma parcela muito pequena dos casos que serão decididos pelos tribunais e, ainda, serão válidas em razão da legitimidade e do que o autor aponta como "prestígio" dos tribunais, que ocorrerá em virtude dos tantos outros casos em que os tribunais decidiram questões em que não haja grande discricionariedade e em que o núcleo de certeza esteja presente. Para Dworkin, contudo, haverá uma resposta mais correta e essa deve ser a buscada pelos tribunais. 


\section{Assim, para Hart, o sistema de regras dará conta da maioria dos casos e, naqueles em que exista uma zona penumbra, por vezes, o direito será, sim, o que os tribunais dizem que ele é, sendo essas decisões corretas ou incorretas. Defende-se, contudo, que existam respostas mais adequadas à Constituição, mas a problemática sempre irá residir em quem irá atestar essa adequação.}

\section{NOTAS}

1 Observa-se que existem divergências sobre com qual grupo estariam identificados tais autores, como é o caso da classificação de Herbert Hart por Neil MacCormick como pós-positivista enquanto o próprio autor se auto classificava como sendo um positivista e da não intitulação do próprio Dworkin como positivista.

2 Outra divergência encontrada nos dois autores refere-se à relação entre o direito e a moral, a qual, inclusive, se reflete nas dificuldades relativas à classificação de Dworkin, utilizando-se a separação da moral e do direito como critério, como um positivista, ao aceitar uma grande influência moral no direito, como pontua Dimoulis (2006, p. 72) ao considerar que "o autor omite teses presentes em praticamente todos os autores positivistas, como a separação entre o direito, a moral e a política".

3 Dentre os céticos, destaca-se Ferdinand Lassale, que acreditava nos fatores reais do poder, sendo, sua obra "A essência da Constituição" "um clássico do constitucionalismo que desconhece a importância do Direito como instrumento de organização social e, ao mesmo tempo, escrevendo sobre uma Constituição, ensina exatamente o que não deve ser a essência de uma Constituição" (LASSALE, 2007, p. xix).

4 É pertinente trazer a crítica de Maus (2000, p. 7, grifado no original) a respeito da superioridade dos Tribunais e da atuação dos mesmos que aponta que "a 'competência' do Tribunal Constitucional -como de qualquer órgão de controle da constitucionalidade - não deriva mais da própria Constituição, colocando-se em primeiro plano a ela. Tal competência deriva diretamente de princípios de direito suprapositivos que o próprio Tribunal tem desenvolvido em sua atividade constitucional de controle normativo, o que leva a romper com os limites de qualquer 'competência' constitucional.

5 Quanto a essa separação, Nino (1997, p.264, grifado no original) apresenta uma crítica feita à Kelsen quanto à inexistência da mesma, colocando que "como sostiene Joseph Raz, Kelsen ha confundido el hecho de si una leu o norma jurídica es válida (y si la decisión de un juez de aplicarla o no es correcta), con el hecho de que una decisión de un juez, correcta o no, tiene fuerza obligatoria y constituye una res judicata".

6 Streck (2010, p. 239, grifado no original) faz uma interessante reflexão quanto ao juiz Hércules de Dworkin, enfatizando que "uma leitura apressada de Dworkin (e isso também ocorre com quem lê Gadamer como um filólogo, fato que ocorre não raras vezes no direito) dá a falsa impressão de que Hércules representa o portador de uma 'subjetividade assujeitadora'....] Dworkin e Gadamer, cada um ao seu modo, procuram controlar esse subjetivismo e essa subjetividade solipsista". 


\section{REFERÊNCIAS}

ATIENZA, Manuel. Constitucionalismo, Globalización y Derecho. In: CARBONELL, Miguel; JARAMILLO, Leonardo García. El Canon Neoconstitucional. Madrid: Trotta, 2010.

BITENCOURT, Caroline Müller. Existe espaço para a argumentação que considere "aspectos morais" na decisão judicial no constitucionalismo contemporâneo? In: GORCZEVSKI, C.; LEAL, M. C. H. (Orgs.). Constitucionalismo Contemporâneo: concretizando direitos. Curitiba: Multideia, 2013.

DIMOULIS, Dimitri. Positivismo Jurídico: Introdução a uma teoria do direito e defesa do pragmatismo jurídico-político. São Paulo: Método, 2006.

DWORKIN, Ronald. 0 império do Direito. São Paulo: Martins Fontes, 2007a.

DWORKIN, Ronald. Uma questão de princípio. São Paulo: Martins Fontes, 2007b.

FERRAZ JUNIOR, Tércio Sampaio. Introdução ao Estudo do Direito. Técnica, Decisão, Dominação. São Paulo: Atlas S. A., 2011.

GUEST, Stephen. Ronald Dworkin. Rio de Janeiro: Elsevier, 2010.

HART, Herbert L. A. Os fundamentos de um sistema jurídico. In: .0 conceito de Direito. Lisboa: Fundação Calouste Gulbenkian, 1994.

LASSALE, Ferdinand. A Essência da Constituição. Rio de Janeiro: Lumen Juris, 2007.

MACCORMICK, Neil. H. L. A. Hart. Rio de Janeiro: Campus, 2010.

MAUS, Ingeborg. Judiciário como superego da sociedade: o papel da atividade jurisprudencial na "sociedade órfã". Tradução de Martonio Lima e Paulo Albuquerque. Novos Estudos - CEBRAP, São Paulo, n. 58, p. 193-202, nov. 2000. 
MÜLLER, Fredrich. Quem é o povo?.7. ed. São Paulo: Revista dos Tribunais, 2013.

NINO, Carlos Santiago. La constitución de la democracia deliberativa. Barcelona: Gedisa, 1997.

STRECK, Lenio Luiz. Hermenêutica, constituição, anatomia do Direito e o Direito Fundamental a obter respostas adequadas (corretas). In: FERNANDES, Bernardo Gonçalves. Interpretação Constitucional: reflexões sobre (a nova) hermenêutica. Salvador: Juspodivm, 2010.

. Jurisdição Constitucional e hermenêutica: uma nova crítica do Direito. Porto Alegre: Livraria do Advogado, 2002.

Recebido em: 17-05-2018

Aprovado em: 09-07-2019

\section{Maria Valentina de Moraes}

Doutoranda no Programa de Pós-Graduação Stricto Sensu em Direitos Sociais e Políticas Públicas da Universidade de Santa Cruz do Sul - UNISC, na linha Dimensões Instrumentais das Políticas Públicas. Bolsista PROSUC/CAPES. Mestre em Direito pela Universidade de Santa Cruz do Sul - UNISC, com bolsa PROSUC/ CAPES. Membro do Grupo de Pesquisa Jurisdição Constitucional aberta: uma proposta de discussão da legitimidade e dos limites da jurisdição constitucional - instrumentos teóricos e práticos", vinculado ao CNPq e coordenado pela professora Pós-Dra Mônia Clarissa Hennig Leal.

Lattes: http://lattes.cnpq.br/2400734786644430.

E-mail: mariavalentina.23@hotmail.com

\section{Mônia Clarissa Hennig Leal}

Pós-doutora pela Universität Heidelberg (Ruprecht-Karls), doutora em Direito pela Universidade do Vale do Rio dos Sinos, e doutora (sanduíche) pela Universitat Heidelberg (Ruprecht-Karls) (2004), mestre em Direito pela Universidade de Santa Cruz do Sul. Professora concursada da Universidade de Santa Cruz do Sul, nos cursos de graduação, especialização, mestrado e doutorado em Direito. Bolsista de produtividade em pesquisa do CNPq. Coordenadora do grupo de pesquisa "Jurisdição Constitucional aberta". Coordenadora do Programa 
de Pós-Graduação em Direito - Mestrado e Doutorado da Universidade de Santa Cruz do Sul - UNISC. Professora Visitante junto à Ernst-Moritz-Arndt Universität Greifswald, Alemanha. Pesquisadora Visitante junto à Ruprecht-Karls Universität Heidelberg, Alemanha e junto à Paris-Lodron Universität Salzburg, Áustria.

E-mail: moniah@unisc.br

Universidade de Santa Cruz do Sul - UNISC. Programa de Pós-Graduação em Direito. Av. Independência, 2293 - Universitário, Santa Cruz do Sul - RS, 96815-900. 
